\title{
1. ASPECTOS DE INCONSTITUCIONALIDAD DE LA LEY ORGÁNICA 5/1992, DE 29 DE OCTUBRE, DE REGULACIÓN DEL TRATAMIENTO AUTOMATIZADO DE LOS DATOS DE CARÁCTER PERSONAL
}

\author{
DIEGO LÓPEZ GARRIDO \\ Catedrático de Derecho Constitucional
}




\section{SUMARIO}

1. Objeto del dictamen.-11. Los Criterios interpretativos.-1. El artículo 18.4 CE.-2. El artículo 10.2 CE.-III. AsPECTOS DE INCONSTItUCIONALIDAD DE LA LORTAD.-1. Artículo 5.3 de la LORTAD.-2. Artículo 17.1.-3. Artículo 19.1.-4. Artículo 20.-5. Artículo 21.1.-6. Artículo 22. 1.-7. Artículo 22.2.-8. Disposición Final Segunda.-Conclusiones. 
Revista de Derecho Político, núm. 38, 1994, pp. 11-35

\title{
49. ASPECTOS DE INCONSTITUCIONALIDAD DE LA LEY ORGÁNICA 5/1992, DE 29 DE OCTUBRE, DE REGULACIÓN DEL TRATAMIENTO AUTOMATIZADO DE LOS DATOS DE CARÁCTER PERSONAL
}

\author{
POR \\ DIEGO LÓPEZ GARRIDO \\ Catedrático de Derecho Constitucional
}

\section{OBJETO DEL DICTAMEN}

A solicitud de la Comisión de Libertades e Informática se realiza el presente Dictamen, que consiste en estudiar los aspectos que puedan considerarse inconstitucionales en la Ley Orgánica 5/1992, de 29 de octubre, de regulación del tratamiento automatizado de los datos de carácter personal (LORTAD).

La Ley Orgánica 5/1992, publicada en el "Boletín Oficial del Estadon de 31 de octubre de 1992, desarrolla el artículo 18.4 de la Constitución Española (CE), que dice:

"La Ley limitará el uso de la informática para garantizar el honor y la intimidad personal y familiar de los ciudadanos y el pleno ejercicio de sus derechos".

El artículo 18.4 de la Constitución no tiene, excepto en el caso de la Constitución de Portugal, preceptos comparables con otras Constituciones. Es lógico, dado el carácter tan reciente del fenómeno de la informática, cuyo desarrollo, al ir unido al potente uso de las telecomunicaciones, ha llevado a plantearse a los legisladores la necesidad de limitar 
su uso en cuanto que pudiera afectar de forma grave al derecho a la intimidad.

El artículo 18.4 de la Constitución se inscribe dentro de un precepto dedicado a la protección de la intimidad en general. El artículo $18.4 \mathrm{se}$ refiere a una dimensión de la intimidad, aquella que tiene que ver con las informaciones sobre la vida de una persona que, de tal modo determinen el ámbito de lo que propiamente podriamos llamar su personalidad, que podrían, manejados por terceros $y$, fundamentalmente, por los poderes públicos, violentar el principio de la dignidad de la persona, de los derechos inviolables que le son inherentes, del libre desarrollo de su personalidad, todos ellos valores establecidos en el artículo 10 de nuestra Constitución.

Probablemente, esto que cabe denominar como intimidad informativa tuvo su desarrollo más elocuente en la sentencia del Tribunal Constitucional alemán de 15 de diciembre de 1983 sobre la Ley del Censo de 31 de marzo de 1982. A ella nos referiremos más adelante.

La importancia del problema llegó a tal extremo que el Consejo de Europa promovió el Convenio de 28 de enero de 1981 «para la protección de las personas con respecto al tratamiento automatizado de datos de carácter personal». Este Convenio fue ratificado en España mediante Instrumento de 27 de enero de 1984 y es, sin duda, el punto de partida sobre el que se apoya la Ley Orgánica cuyo estudio será objeto de este Dictamen.

El Dictamen se va a dividir en dos partes. En la primera de ellas intenta establecer los criterios interpretativos que van a ser necesarios para examinar el contenido de la Ley 5/1992 en relación con la Constitución Española. A ese respecto, se pondrá de relieve el contenido esencial del derecho regulado en el artículo 18.4 de la Constitución y se establecerán los principios básicos que deben servir de apoyo hermenéutico, previstos en los convenios internacionales, que deben ser tenidos en cuenta por el intérprete de la Constitución, según prescribe el artículo 10 de nuestra Norma fundamental.

Una vez fijados estos criterios interpretativos, iremos estudiando sucesivamente aquellos preceptos que entendemos pueden incurrir en vicio de inconstitucionalidad, dentro de la Ley Orgánica 5/1992. 


\section{CRITERIOS INTERPRETATIVOS}

\section{El artículo $\mathbf{1 8 . 4}$ de la Constitución y el contenido esencial del derecho a la intimidad informativa}

Naturalmente, el elemento básico que nos da un criterio interpretativo para dilucidar si un precepto de la Ley 5/1992 (en lo sucesivo, LORTAD) es inconstitucional o no es el artículo, antes citado y reproducido, 18.4 de la Constitución. Vamos a reiterar su contenido:

"La Ley limitará el uso de la informática para garantizar el honor y la intimidad personal y familiar de los ciudadanos $y$ el pleno ejercicio de sus derechos".

Dado que hasta ahora no ha existido regulación legislativa que desarrolle el artículo 18.4 de la Constitución, ni tampoco ha habido ningún recurso de amparo sobre esa cuestión que se haya planteado ante el Tribunal Constitucional, no existe jurisprudencia de éste que haya interpretado ese artículo.

Por eso, es especialmente importante el tener en cuenta, para conocer el sentido del artículo 18.4 en relación con la Ley que lo desarrolla, aquello a que se refiere el artículo 53.1 de nuestra Constitución, y que califica como "contenido esencial».

En efecto, el artículo 53.1 CE establece una importante garantía de los derechos fundamentales, entre los que está el derecho a la intimidad. Se trata de una garantía frente al legislador y frente al poder ejecutivo. Garantía frente al poder ejecutivo en cuanto que "sólo por ley" podrá "regularse el ejercicio de tales derechos y libertades». Y garantía frente al legislador - y ésta es la que nos interesa en este momento- porque esa regulación por ley "en todo caso deberá respetar su contenido esencial».

Así que la remisión que el artículo 18.4 hace al legislador no es una delegación en blanco que el constituyente hiciese al Parlamento. En todo caso, cuando el legislador desarrolla el artículo 18.4 tiene que respetar el "contenido esencial" del derecho o los derechos que están protegidos en ese precepto constitucional.

Para determinar el contenido esencial del derecho a la intimidad informativa protegido en el precepto que examinamos es instrumento hermenéutico fundamental la llamada voluntad del legislador, que puede 
deducirse, entre otras cosas, de los debates parlamentarios. A ese respecto, queremos recordar que la intervención del representante del grupo Minoria Catalana que, en la discusión constituyente, defendió una enmienda al que luego sería artículo 18.4 de la Constitución (enmienda n.o117), que consiguió fuese aceptada, y en la que amplió considerablemente el ámbito de protección del artículo 18.4, de modo que éste no se limita a una mera protección de la intimidad y el honor, sino que se extiende al ejercicio de los derechos, de todos los derechos, por parte de los ciudadanos, como se deduce de la redacción definitiva del precepto constitucional.

Merece la pena reproducir las palabras del parlamentario que en su momento defendió el texto de la citada enmienda, que fue incluida en la parte final del artículo 18.4:

"Cuando la Ponencia limita este uso (de la informática) a los daños que puedan producirse al honor, a la intimidad personal y familiar, se queda simplemente en una reflexión parcial de los problemas, porque lo realmente grave aparece cuando esta información que puede dañar el honor incide en el ejercicio de los derechos por parte de los ciudadanos, es decir, cuando un ciudadano, por ejemplo, deseando constituir una asociación o promocionar una reunión, o bien practicar una actividad económica, encuentra que, por razón de una información de la que él no es conocedor y respecto de la cual no puede incluso ni pronunciarse en muchas ocasiones, se limita de tal manera el ejercicio de sus derechos que se ve colocado en una situación de inferioridad y desigualdad frente a los ciudadanos. Por esta razón... nosotros insistimos en nuestra enmienda que fundamentalmente supone el incorporar entre los límites de la informática el que se garantice el pleno ejercicio de los derechos por parte de los ciudadanos".

No hay duda de que el constituyente quiso darle a los derechos garantizados por el artículo 18.4 una proyección extraordinariamente amplia. La Constitución española obliga a que el límite al uso de la informática sea especialmente sólido y eficaz para que puedan garantizarse, no sólo el derecho a la intimidad o al honor, sino los demás derechos y libertades, que pudieran verse afectados por el uso inmoderado de la informática. Por tanto, el derecho a la intimidad informativa configurado en el artículo 18.4 es un derecho fundamental de naturaleza y contenido muy amplios, y así debe interpretarse a la hora de establecer la posible vulneración de ese precepto por la acción del legislador.

El artículo 18.4, como todo derecho fundamental, tiene una superior vigencia, una superior eficacia, respecto de otros preceptos constitucionales o legales. Así, el artículo 18.4 predomina en cuanto pudiera con- 
tradecirse por un hipotético desarrollo legislativo del artículo 105.b de la Constitución, que señala que la Ley regulará

"el acceso de los ciudadanos a los archivos y registros administrativos, salvo en lo que afecte a la seguridad y defensa del Estado, la averiguación de los delitos y la intimidad de las personas".

Debemos completar lo anterior con la mención de un artículo de la CE que es esencial a nuestros efectos: el artículo 10.1 de la Constitución, que dice:

"La dignidad de la persona, los derechos inviolables que le son intérentes, el libre desarrollo de la personalidad, el respeto a la Ley y a los derechos de los demás son fundamento del orden político y de la paz social".

Efectivamente, como señaló en su día el Tribunal Constitucional alemán en la ya citada sentencia de 15 de diciembre de 1983, en las condiciones de la elaboración moderna de datos, la protección del individuo contra la recogida, almacenamiento, utilización y difusión de sus datos personales queda englobada en el derecho general de protección de la persona, de su dignidad. Ese derecho garantiza la facultad del individuo de determinar fundamentalmente por sí mismo la divulgación y la utilización de los datos referentes a su persona.

Por eso, el Tribunal alemán señaló que las limitaciones que pudieran establecerse a ese derecho a la "autodeterminación informativa" sólo eran admisibles en el marco de un interés general superior y necesitaban un fundamento legal basado en la Constitución, que debe corresponder al imperativo de claridad normativa inherente al Estado de Derecho. En su regulación debe el legislador observar, además, el principio de la proporcionalidad y tiene que adoptar precauciones de índole organizativa y de derecho procesal susceptibles de contrarrestar el peligro de vulneración del derecho a la salvaguardia de la personalidad.

Todo ello configura lo que, de acuerdo con el artículo 53.1 de la Constitución, podríamos denominar contenido esencial del derecho fun: damental protegido en el artículo 18.4 de la Constitución. Ese contenido esencial se corresponde con la definición que de ese concepto básico de nuestro derecho constitucional ha establecido el Tribunal Constitucional español en la Sentencia 11/1981, de 8 de abril, con las siguientes palabras: 
"Constituyen el contenido esencial de un derecho subjetivo aquellas facultades o posibilidades de actuación necesarias para que el derecho sea recognoscible como pertinente al tipo descrito y sin las cuales deja de pertenecer a este tipo y tiene que pasar a quedar comprendido en otro, desnaturalizándose...

Se puede entonces hablar de una esencialidad del contenido del derecho para hacer referencia a aquella parte del contenido del derecho que es absolutamente necesaria para que los intereses jurídicamente protegibles, que dan vida al derecho, resulten real, concreta y efectivamente protegidos. De este modo, se rebasa o se desconoce el contenido esencial cuando el derecho queda sometido a limitaciones que lo hacen impracticable, lo dificultan más allá de lo razonable o lo despojan de la necesaria protección...

Se entiende por contenido esencial aquella parte del contenido de un derecho sin la cual éste pierde su peculiaridad, o, dicho de otro modo, lo que hace que sea recognoscible como derecho perteneciente a un determinado tipo. Es también aquella parte del contenido que es ineludiblemente necesaria para que el derecho permita a su titular la satisfacción de aquellos intereses para cuya consecución el derecho se otorga."

Como vemos, el Tribunal Constitucional hace una definición de lo que hay que entender por contenido esencial que es perfectamente aplicable, como no podía ser de otro modo, a nuestro objeto. Conocer el contenido esencial del derecho o de los intereses protegidos en el artículo 18.4 requiere seguir las directrices señaladas por el Tribunal Constitucional español, completadas con las ideas -que nos parecen perfectamente aplicables a nuestro supuesto- anteriormente expuestas por el Tribunal Constitucional alemán. Ello, en convergencia con la dicción literal del artículo 18.4 de la Constitución, nos lleva a la conclusión de que el derecho a la intimidad informativa previsto en este precepto es de una enorme amplitud $y$, en consecuencia, su contenido esencial condiciona de una forma amplia al legislador, a la hora del desarrollo del mismo.

Todo lo anterior se ve completado por los tratados internacionales que se refieren a los derechos protegidos en el artículo 18.4 de la Constitución. Estos textos contribuyen a configurar, como veremos, el contenido esencial de los derechos garantizados en el artículo 18.4, que no puede ser en ningún caso traspasado por el legislador. 


\title{
2. El artículo $\mathbf{1 0 . 2}$ de la Constitución y los tratados internacionales sobre Derechos Humanos
}

\author{
El artículo 10.2 de nuestra Constitución dice:
}

\begin{abstract}
"Las normas relativas a los derechos fundamentales y a las libertades que la Constitución reconoce se interpretarán de conformidad con la Declaración Universal de Derechos Humanos y los tratados y acuerdos internacionales sobre las mismas materias ratificados por España».
\end{abstract}

El criterio interpretativo expresado en el artículo 10.2 es capital. Dé alguna forma establece un bloque de constitucionalidad entre los derechos fundamentales regulados en nuestra Constitución y los tratados que sobre los mismos hayan sido ratificados por España. Es un criterio interpretativo absolutamente claro y evidente, que nuestro Tribunal Constitucional ha seguido al pie de la letra y sin ningún tipo de duda.

Así, en la sentencia 78/1992, de 20 de diciembre (fundamento jurídico 4), el Tribunal Constitucional dice:

"Como señalábamos en la anterior sentencia número 62/1982, de 15 de octubre ("Boletín Oficial del Estado" de 17 de noviembre, fundamento jurídico 1), la Constitución se inserta en un contexto internacional en materia de derechos fundamentales y libertades públicas por lo que hay que interpretar sus normas en esta materia de conformidad con la Declaración Universal de Derechos Humanos y los tratados y acuerdos internacionales que menciona el precepto. $Y$ añadimos ahora no sólo las normas contenidas en la Constitución, sino todas las del ordenamiento relativas a los derechos fundamentales y libertades públicas que reconoce la Norma fundamental».

Por tanto, el Tribunal Constitucional extiende la aplicación de los tratados internacionales, como norma interpretativa a un nivel de rango constitucional, no sólo a la interpretación de la Constitución sino de las normas de desarrollo de la misma, entre ellas, como es lógico, la LORTAD.

Pues bien, respecto a la interpretación del artículo 18.4, hay que considerar los siguientes tratados y acuerdos internacionales:

En primer lugar, el artículo 12 de la Declaración Universal de los Derechos Humanos, que señala: 
"Nadie será objeto de injerencias arbitrarias en su vida privada, la de su familia, domicilio, correspondencia, ni de ataques a su honor y reputación. Toda persona tiene derecho a la protección de la Ley contra estas injerencias o ataques".

Por su parte, el artículo 8 del Convenio para la protección de los derechos humanos y de las libertades fundamentales (Convenio de Roma de 1950) dice:

«1. Toda persona tiene el derecho al respeto de su vida privada y familiar, de su domicilio y de su correspondencia.

2. No podrá haber injerencia de la autoridad pública en el ejercicio de este derecho, sino en tanto en cuanto esta injerencia esté prevista por la ley y constituya una medida que, en una sociedad democrática, sea necesaria para la seguridad nacional, la seguridad pública, el bienestar económico del país, la defensa del orden y la prevención del delito, la protección de la salud o de la moral, o la protección de los derechos y las libertades de los demás."

Según el Tribunal de Derechos Humanos, las autoridades nacionales disponen de un "margen de apreciación» al proceder a la evaluación de si una determinada medida de limitación del derecho a la intimidad es "necesaria en una sociedad democrática". Pero las decisiones de las autoridades nacionales se someten al control de los órganos del convenio europeo (sentencia Handyside, de 7 de diciembre de 1976, parágrafo 49) $y$, además, una interferencia en los derechos del individuo sólo puede ser considerada "necesaria en una sociedad democrática" si está en proporción con el objeto legítimo perseguido (sentencia Dudgeon, de 22 de octubre de 1981, parágrafo 53).

Conviene también citar, entre los grandes textos o convenios sobre derechos humanos, el artículo 17 del Pacto Internacional de Derechos Civiles y Políticos, Pacto de Nueva York de 1966, que se refiere al derecho a la vida privada en términos parecidos a la Declaración Universal de los Derechos Humanos.

Por último, el texto o tratado internacional más importante a nuestros efectos, como elemento interpretativo del artículo 18.4 de la Constitución es, sin duda, el ya mencionado Convenio de 28 de enero de 1981 para la protección de las personas respecto al tratamiento automatizado de datos de carácter personal, ratificado por España el 27 de enero de 1984. De acuerdo con los artículos 96.1 y 10.2 de la Constitución, este Convenio forma parte del ordenamiento interno español $y$, sobre todo, 
tiene una eficacia interpretativa directa a la hora de fijar el contenido esencial de los derechos garantizados en el artículo 18.4 de la Constitución.

El Convenio de 1981 establece unos principios básicos respecto a los datos de carácter personal objeto de tratamiento automatizado, y que se regulan en los artículos 5, 6 y 8 del mismo:

- Principios de lealtad y legalidad.

- Principio de proporcionalidad respecto a su finalidad.

- Principio de exactitud.

- Principio de seguridad.

- Principio de protección especial de los datos sensibles.

- Principio de acceso a los ficheros automatizados y a los datos personales, que se extiende al derecho a la publicidad de los ficheros, al conocimiento de los datos que afectan a un individuo, a la rectificación de esos datos y a un recurso si no se ha obtenido la pretensión planteada de acuerdo con las garantías anteriores.

El Convenio de 1981 establece también determinadas excepcionés y restricciones a los principios y derechos anteriormente señalados. A esas excepciones se refiere el artículo 9 del Convenio de 1981, cuyo texto completo reproducimos por su importancia a los efectos de este dictamen:

"1. No se admitirá excepción alguna en las disposiciones de los arțículos 5,6 y 8 del presente Convenio, salvo que sea dentro de los límités que se definen en el presente artículo.

2. Será posible una excepción en las disposiciones de los artículos 5 , 6 y 8 del presente Convenio cuando tal excepción, prevista por ley de la Parte, constituya una medida necesaria en una sociedad democrática.

a) para la protección de la seguridad del Estado, de la seguridad pública, para los intereses monetarios del Estado o para la represión de infracciones penales;

b) para la protección de la persona concernida y de los derechos y libertades de otras personas. 
3. Podrán preverse por la ley restricciones en el ejercicio de los derechos a que se refieren los párrafos b), c) y d) del artículo 8 para los ficheros automatizados de datos de carácter personal que se utilicen con fines estadísticos o de investigación científica, cuando no existan manifiestamente riesgos de atentado a la vida privada de las personas concernidas."

En suma, los derechos garantizados por el artículo 18.4 de la Constitución son todos los establecidos en nuestra Constitución en la medida en que puedan verse afectados por el uso de la informática. Esto significa que la potencialidad de este precepto constitucional es enorme. Además, la configuración amplia del artículo 18.4 lleva a configurar los derechos de intimidad informativa como derechos prestacionales, es decir, que no sólo requieren una actitud respetuosa por parte de los poderes públicos sino también una acción positiva, beligerante, de defensa de esa intimidad, de la dignidad de la persona, del derecho al libre desarrollo de la personalidad, frente al uso ilícito o abusivo de la informática. Todo ello requiere una regulación legal, cuyos principios están anticipados en el Convenio del Consejo de Europa de 1981, que, por ello, se configura como el texto legal de referencia a la hora de fijar el contenido esencial de los derechos protegidos por el artículo 18.4 de la Constitución, y que, por tanto, no pueden ser vulnerados por el legislador, en nuestro caso, por la LORTAD.

El Tribunal Constitucional, en una de sus más recientes sentencias, ha confirmado la certeza de las anteriores consideraciones, en cuanto que subraya el carácter determinante de los tratados internacionales a la hora de constituirse en criterio interpretativo decisivo de los preceptos que, en nuestra Norma fundamental, regulan, proclaman y garantizan los derechos fundamentales. En la sentencia 281/1991, fundamento jurídico 5, señala que el precepto constitucional definidor del derecho o libertad debe ser interpretado "en cuanto a los perfiles exactos de su contenido, de conformidad con el tratado o acuerdo internacional". Los tratados internacionales, pues, dan el "perfil exacto" del derecho garantizado en la Constitución o, lo que es lo mismo, su contenido esencial. Es decir, el tratado o convenio internacional sobre derechos humanos, en su contenido, actúa como parámetro de validez constitucional. Esto es lo que se reitera en la sentencia 64/1991, de 22 de marzo, fundamento jurídico 4, en la que el Tribunal Constitucional señala que los derechos fundamentales y libertades públicas han de interpretarse en cuanto a su "contenido $\mathrm{y}$ a/cance", "de conformidad con los tratados y acuerdos internacionales a que hace referencia el artículo $10.2 \mathrm{CE}$.

En aplicación de los anteriores criterios cabría concluir en que una contradicción nítida entre la LORTAD y los convenios y textos internacio- 
nales antes señalados, en especial el Convenio del Consejo de Europa de 1981, significaría que la LORTAD, en ese concreto aspecto, sería inconstitucional, por contravenir el artículo 18.4 de la Constitución, en relación con los artículos 10.2 y 53.1 de nuestra Norma fundamental. Efectivamente, por el juego de estos tres artículos, hay que entender que el Convenio de 1981 contribuye a determinar el perfil exacto, o sea, el contenido esencial, de los derechos garantizados en el artículo $18.4 \mathrm{y}$, por tanto, una contradicción de ese Convenio respecto de la LORTAD, habría qựe entenderla como vulneración del artículo 53.1 CE y desencadenante de la inconstitucionalidad del precepto de la LORTAD de que se trate.

\section{ASPECTOS DE INCONSTITUCIONALIDAD DE LA LORTAD}

Siguiendo los criterios interpretativos que hemos desarrollado èn el apartado anterior de este Dictamen, vamos a ir examinando aquellos preceptos de la LORTAD que consideramos incurren en inconstitucionalidad. Utilizaremos, a ese respecto, la referencia fundamental del Convenio Europeo de 1981, pero también otros aspectos de nuestro texto constitucional que directamente se ven vulnerados por las disposiciones de la Ley.

\section{Artículo 5.3 de la LORTAD}

El artículo 5 de la Ley 5/1992 dice:

«1. Los afectados a los que se soliciten datos personales deberán ser previamente informados de modo expreso, preciso o inequívoco:

a) De la existencia de un fichero automatizado de datos de carácter personal, de la finalidad de la recogida de éstos y de los destinatarios de la información.

b) Del carácter obligatorio o facultativo de su respuesta a las preguntas que les sean planteadas.

c) De las consecuencias de la obtención de los datos o de la negativa a suministrados. 
d) De la posibilidad de ejercitar los derechos de acceso, rectificación y cancelación.

e) De la identidad y dirección del responsable del fichero.

2. Cuando se utilicen cuestionarios $u$ otros impresos para la recogida, figurarán en los mismos, en forma claramente legible, las advertencias a que se refiere el apartado anterior.

3. No será necesaria la información a que se refiere el apartado 1 si el contenido de ella se deduce claramente de la naturaleza de los datos personales que se solicitan o de las circunstancias en que se reclaman.»

A nuestro juicio, el apartado 3 del artículo 5 es inconstitucional. La excepción que en él se hace respecto de las obligaciones de información a que se refiere el apartado 1 pueden llevar, por su extrema abstracción y vaguedad, a un vaciamiento de las garantías de ese apartado. Eso significaría no sólo una vulneración del artículo 18.4, en cuanto que habría un grave peligro para la intimidad, sino también del artículo 9.3 de la Constitución, que garantiza la seguridad jurídica.

El artículo 5.1 señala, con toda propiedad, que la información a los afectados que soliciten datos personales debe ser expresa, precisa e inequivoca. Son calificativos enormemente rigurosos, que, como decimos, se vacían de contenido en el apartado 3 en cuanto que éste permite no dar esa información por hechos tan poco definibles y tan poco concretos como la "naturaleza de los datos personales que se solicitan" o las "circunstancias" en que se reclaman. Estos términos conceden al funcionario o empleado encargado de suministrar los datos, un ámbito de discrecionalidad tan amplio que se confunde con la arbitrariedad y que hace perder todo sentido a las garantías establecidas en el apartado 1 del artículo 5.

Por otro lado, por si eso no fuera suficiente, resulta que el artículo 5.3 de la Ley 5/1992 contradice la garantía establecida en el artículo 8 a) del Convenio de 1981, según el cual cualquier persona debe poder conocer la existencia de un fichero automatizado de datos de carácter personal y sus finalidades principales. Las excepciones a lo anterior establecidas en el artículo 9 se refieren a la protección de la seguridad del Estado, de la seguridad pública, los intereses monetarios del Estado o la represión de infracciones penales, así como la protección de la persona concernida y los derechos y libertades de otras personas. Ninguna de estas excepciones son encajables en el artículo 5.3. Su redacción, repetimos, es extremadamente abstracta y vaporosa y excede, con toda evidencia, de las excepciones tasadas establecidas en el artículo 9 del Convenio de Eu- 
ropa de 1981. El artículo 5.3 vulnera, pues, el contenido esencial del derecho protegido por el artículo 18.4 de la Constitución.

\section{Artículo 17.1}

El artículo 17.1 de la LORTAD dice:

"Las actuaciones contrarias a lo dispuesto en la presente Ley pueden ser objeto de reclamación por los afectados ante la Agencia de Protección de Datos en la forma que reglamentariamente se determine».

Este artículo remite a norma de rango inferior a Ley la regulación procesal de los Recursos contra actuaciones de los poderes públicos contrarias a la LORTAD. Es decir, remite a un Reglamento la regulación de la protección de los derechos fundamentales protegidos por el artículo 18.4 CE y por la propia LORTAD.

Esa remisión al Reglamento que hace el artículo 17.1 LORTAD es, a todas luces, contraria al principio de reserva de Ley que se deduce del artículo 53.1 CE en relación con el 18.4 CE y el 24.1 CE. Dado que se trata de una materia procesal que garantiza la protección de derechos fundamentales, los eventuales recursos ante la Agencia de Protección de Datos tienen que ser objeto de Ley. En la medida en que el artículo 17.1 LORTAD prevé que esa regulación sea por reglamento, este precepto es inconstitucional.

\section{Artículo 19.1}

El artículo 19.1 de la LORTAD dice:

"Los datos de carácter personal recogidos o elaborados por las Administraciones Públicas para el desempeño de sus atribuciones no serán cedidos a otras Administraciones Públicas para el ejercicio de competencias diferentes o de competencias que versen sobre materias distintas, salvo cuando la cesión hubiese sido prevista por las disposiciones de creación del fichero o por disposición posterior de igual o superior rango que regule su uson. 
Este artículo 19.1 desarrolla uno de los principios básicos establecidos por el Convenio de 1981 sobre la protección de la intimidad y la personalidad respecto del tratamiento automatizado de datos personales. Se trata del principio previsto en el artículo $5 \mathrm{~b}$ ) de ese Convenio, según el cual los datos personales "se registrarán para finalidades determinadas y legítimas y no se utilizarán de una forma incompatible con dichas finalidades". Este principio es reproducido por el artículo 4.2 de la LORTAD, que constituye, por tanto, el fundamento del precepto que examinamos junto con el importante artículo 11.1 de la propia LORTAD, que dice:

"Los datos de carácter personal objeto del tratamiento automatizado sólo podrán ser cedidos para el cumplimiento de fines directamente relacionados con las funciones legítimas del cedente $y$ del cesionario con el previo consentimiento del afectado".

Así pues, la cesión de datos a terceros está rodeada de especiales garantías en la Ley y en el Convenio Europeo de 1981. La cesión de datos personales, merced a la potencia y a la capacidad tecnológica actual, es una de las fuentes de mayor peligro de divulgación de esos datos de atentado a la seguridad de los mismos, y, en definitiva, de vulneración de la intimidad de la persona y de la dignidad de la misma. Por eso, todos los textos internacionales, el derecho comparado y toda la regulación juridica de los países de nuestro entorno hacen de las garantías de la no cesión a terceros uno de los aspectos nucleares de la garantía del derecho a la intimidad informativa. Constituye, sin duda, "contenido esencial» de ese derecho, a los efectos del artículo 53.1 de la Constitución.

Sin embargo, el artículo 19.1, sorprendentemente, permite la cesión de datos en poder de las Administraciones Públicas a otras Administraciones Públicas siempre que eso esté permitido por la disposición de creación de ficheros. Esa disposición de creación del fichero puede tener rango reglamentario, según se desprende del artículo 18.1 de la LORTAD («disposición general publicada en el "Boletín Oficial del Estado" o "Diario Oficial" correspondiente"). La consecuencia de ello es que una disposición reglamentaria puede, por si misma, determinar que unos datos personales recogidos por una Administración Pública pueden ser cedidos a otra, lo que afecta directamente al contenido esencial del derecho fundamental protegido por el artículo 18.4 CE. No hay, además, ningún tipo de condicionamiento a esas disposiciones reglamentarias. El artículo 19.1 LORTAD no las establece. Hay una remisión en blanco al poder ejecutivo por parte del artículo 19.1 para que pueda prever la cesión de Administraciones Públicas a otras de datos de carácter personal. El artículo 19.1 LORTAD, por tanto, vulnera, no sólo el artículo 9.3 CE (principio de 
legalidad) y, desde luego, la reserva de ley establecida en el artículo 53.1 de la Constitución.

\title{
4. El artículo 20
}

El artículo 20 es, sin duda, uno de los más polémicos de la LOR$T A D$, en cuanto que se refiere a la recogida y tratamiento automatizado de datos por las Fuerzas y Cuerpos de Seguridad sin el consentimiento de las personas afectadas. Asimismo, se refiere a la recogida y tratamiento de los datos sensibles, los más especialmente protegidos, que son definidos en el artículo 7 de la Ley.

El artículo 20 en su apartado 2 dice:

\begin{abstract}
"La recogida y tratamiento automatizado para fines policiales de datos de carácter personal por las Fuerzas y Cuerpos de Seguridad sin consentimiento de las personas afectadas, están limitados a aquellos supuestos y categorías de datos que resulten necesarios para la prevención de un peligro real para la seguridad pública o para la represión de infracciones penales, debiendo ser almacenados en ficheros específicos establecidos al efecto, que deberán clasificarse por categorias, en función de su grado de fiabilidad".
\end{abstract}

Este precepto justifica la recogida de datos sin consentimiento de las personas afectadas por razones que encajan, ciertamente, en las excepciones a que se refiere el artículo 9.2 del Convenio de 1981. En ese sentido, cabría, siguiendo los criterios interpretativos consistentes en fijar como punto de referencia el Convenio Europeo, entender como no contrarios al contenido esencial del artículo 18.4 de la Constitución las prescripciones del artículo 20.2 de la LORTAD. El problema de su inconstitucionalidad aparece en la medida en que esta potestad de las Fuerzas y Cuerpos de Seguridad no está suficientemente controlada, como veremos en el artículo 21 de la LORTAD. Esto es lo que hace que la falta de control, que luego examinaremos, desencadena por efecto inducido una inconstitucionalidad en las prescripciones del artículo 20.2 .

En cuanto al artículo 20.3, resulta ser un precepto especialmente delicado, ya que se refiere a los datos sensibles. El artículo 7 de la Ley dice lo siguiente en sus apartados 2 y 3 : 
«2. Sólo con consentimiento expreso del afectado podrán ser objeto de tratamientos automatizados los datos de carácter personal que revelen su ideología, religión o creencias.

3. Los datos de carácter personal que hagan referencia al origen racial, a la salud y a la vida sexual sólo podrán ser recabados, tratados automáticamente $y$ cedidos cuando, por razones de interés general, así lo disponga una ley o el afectado consienta expresamente."

Esta garantía desaparece en el caso de datos recogidos y tratados por las Fuerzas y Cuerpos de Seguridad para los fines de una investigación concreta. En efecto, el artículo 20.3 dice:

"La recogida y tratamiento por las Fuerzas y Cuerpos de Seguridad de los datos a que hacen referencia los apartados 2 y 3 del artículo 7, podrán realizarse exclusivamente en los supuestos en que sea absolutamente necesario para los fines de una investigación concreta».

No habría problema de inconstitucionalidad si los datos personales a que hace referencia el artículo 20.3 no fuesen de carácter sensible, ya que los fines de una investigación concreta pueden entenderse incluidos en las excepciones del artículo 9 del Convenio Europeo de 1981. Sin embargo, estamos ante un supuesto de datos que afectan profundamente a la intimidad de una persona $y$, por tanto, la posibilidad de recogida $y$ tratamiento de los mismos sin consentimiento y sin conocimiento del afectado vulnera el artículo 18.4 en la medida en que no hay un control suficiente de esa actividad y en la medida en que no hay justificación objetiva de que sea necesario la recogida de esos datos para la protección de la seguridad pública. Queremos decir con ello que la recogida de datos que afectan a su salud, por las consecuencias de interés general derivadas del no control adecuado de determinadas enfermedades, permite que pueda entenderse la excepción del artículo 20.3. Sin embargo, en los demás casos no parece fácilmente comprensible. La ideología, la religión - la creencia, las costumbres sexuales o de origen racial no deben estar en ningún tipo de fichero automatizado obtenido sin el consentimiento el afectado. Los fines de una investigación concreta no lo justifican porque es muy difícil pensar en una investigación concreta que necesite saber, por ejemplo, de las costumbres sexuales de una persona. Hay que tener en cuenta que la LORTAD se refiere a ficheros automatizados, no a ficheros manuales. Las Fuerzas y Cuerpos de Seguridad pueden tener una serie de datos en ficheros manuales porque esto, por el momento, no está prohibido por ninguna ley. En la LORTAD se habla de ficheros automatizados, y respecto de ellos no es admisible que se traten automáticamente datos que afectan a la intimidad tan profundamente como los llama- 
dos "sensibles». En ese sentido, entendemos que el artículo 20.3 resulta contrario al artículo 18.4 de la Constitución.

\section{Artículo 21.1}

El artículo 21 nos parece de mayor gravedad que el anteriormente comentado. Porque se refiere al control, o mejor dicho, a las excepciones al control de la recogida y tratamiento de datos personales por parte de los poderes públicos.

El artículo en su apartado primero dice:

"Los responsables de los ficheros que contengan los datos a que se refieren los apartados 2, 3 y 4 del artículo anterior podrán denegar el aćceso, la rectificación o la cancelación en función de los peligros que pudieran derivarse para la defensa del Estado o la seguridad pública, la protección y libertades de terceros o las necesidades de las investigaciones que se estén realizando».

El apartado segundo del artículo 21 se refiere a los ficheros de la hacienda pública $y$, en principio, aunque dudosamente constitucional, podría admitirse en la medida en que la defensa de los intereses monetarios constituye una de las excepciones a los principios garantizadores establecidos en el Convenio Europeo de 1981. En cuanto al apartado 3 del artículo 21, su tenor es el siguiente:

«El afectado al que se le niegue, total o parcialmente, el ejercicio de lo's derechos mencionados en los apartados anteriores podrá ponerlo en conocimiento del Director de la Agencia de protección de datos o del Organismo competente de cada Comunidad Autónoma en el caso de ficheros automatizados mantenidos por Cuerpos de Policía propios de éstas, o por las Administraciones Tributarias Autonómicas, quien deberá asegurarse de la procedencia o improcedencia de la denegación".

Como se ve, el posible control por parte de la Agencia de Protección de Datos es nulo. Se trata de un precepto sin prácticamente ningún sentido, ya que la Agencia de Protección de Datos solamente "deberá asegurarse de la procedencia o improcedencia de la denegación", pero no se le da ninguna potestad más. Se trata de algo puramente simbólico. 
Así pues, el artículo 21.1, que es el que, a nuestro juicio, produce una vulneración de la Constitución española, permite denegar unos derechos tan esenciales a la protección de la intimidad respecto del uso de la informática como son el acceso, la rectificación o la cancelación de datos personales que se consideran falsos por parte del afectado. No sólo datos personales en general, sino, muy concretamente, datos sensibles. Esa denegación del acceso puede realizarse en razón de valores como la defensa del Estado o la seguridad pública, la protección de los derechos y libertades de terceros, o las necesidades de las investigaciones que se estén realizando.

En este caso, la comparación con las disposiciones del Convenio Europeo de 1981 podrían llevar a entender que el artículo 21.1 no es contrario a nuestra Constitución. Efectivamente, el artículo 6 del Convenio de 1981 dice que los datos de carácter personal que revelen el origen racial, las opiniones políticas, las convicciones religiosas u otras convicciones, así como los datos de carácter personal relativos a la salud o a la vida sexual, no pueden tratarse automáticamente a menos que el derecho interno prevea garantías apropiadas, garantías que claramente no existen en el caso previsto en el artículo 21.1 de la LORTAD. Sin embargo, el artículo 9 del Convenio permite que se excepcione lo previsto en el artículo 6 del mismo por razones asimilables a las que establece el artículo 21.1 de la LORTAD siempre que constituyan una «medida necesaria en una sociedad democrática».

Como dijimos en el apartado II de este Dictamen, la Jurisprudencia de los órganos del Convenio Europeo de 1950 sobre lo que hay que entender por "medida necesaria en una sociedad democrática" considera que se está en ese caso cuando la medida en cuestión es proporcional al objetivo legítimo perseguido. Pues bien, sin duda que es un objetivo legítimo la defensa del Estado o la seguridad pública y la protección de los derechos y libertades de terceros. Pero no es proporcional a esa finalidad el que los responsables de las Fuerzas y Cuerpos de Seguridad de los ficheros que contengan datos de carácter personal "sensibles" puedan negarse al acceso, rectificación o cancelación de esos datos, que bien pueden ser falsos, del afectado, sin que, además, se exija resolución motivada ni haya ningún tipo de control eficaz sobre esa conducta. En este sentido, debe concluirse en el carácter inconstitucional del artículo 21.1 de la LORTAD en relación con el artículo 20.3 de la misma. 


\title{
6. Artículo 22.1
}

El artículo 22.1 de la LORTAD dice:

\begin{abstract}
"Lo dispuesto en los apartados 1 y 2 del artículo 5 no será aplicable a la recogida de datos cuando la información al afectado impida o dificulte gravemente el cumplimiento de las funciones de control y verificación de las Administraciones Públicas o cuando afecte a la Defensa Nacional, a la Seguridad Pública o a la persecución de infracciones penales o administrativas".
\end{abstract}

Aquí hay una vulneración del artículo 18.4 de la Constitución, en cuanto que se vulnera nítidamente el Convenio Europeo de 1981. El artículo 9 de este Convenio, ya hemos dicho en repetidas ocasiones, permite excepciones a las garantías de las personas en su intimidad y en su vida privada respecto del tratamiento de datos de carácter personal cuando se considera necesaria la protección de la Seguridad del Estado, la Seguridad Pública, los intereses monetarios del Estado o la represión de infracciones penales. Según el artículo 22.1 de la LORTAD, es posible denegar la información al afectado -que es uno de los derechos fundamentales de cualquier regulación del tratamiento automatizado de datos de carácter personal- cuando esa información uimpida o dificulte gravemente el cumplimiento de las funciones de control y verificación de laș Administraciones Públicas". Tampoco está entre las posibles excepciones a las garantías del Convenio de 1981 la persecución de infracciones "administrativas".

El control y verificación de las Administraciones Públicas es un concepto absolutamente abstracto y genérico, que no puede incluirse, desde luego, en el mucho más concreto de seguridad del Estado o de seguridad pública. Asimismo, el que el Convenio Europeo de 1981, en su artículo 9, señale como excepción a las garantías del mismo la represión de infracciones "penales", es indicio claro de que la represión de infracciones "administrativas" no está entre las finalidades que permiten no aplicar esas garantias que la persona tiene respecto el tratamiento automatizado de datos en el Convenio Europeo de 1981, y que prevén los artículos 5,6 y 8 del mismo.

En suma, el artículo 22.1 de la LORTAD es inconstitucional en la frase «impida o dificulte gravemente el cumplimiento de las funciones de control y verificación de las Administraciones Públicas", así como en lá expresión "administrativas", que son supuestos que no se incluyen en el artículo 9 del Convenio de 1981 como excepciones a las garantías de és- 
te. El artículo 22.1 de la LORTAD vulnera el "contenido esencial" de los derechos protegidos en el artículo 18.4 CE.

\section{Artículo 22.2}

El artículo 22 de la LORTAD, en su apartado 2, dice:

"Lo dispuesto en el artículo 14 y en el apartado 1 del artículo 15 no será de aplicación si, ponderados los intereses en presencia, resultase que los derechos que dichos preceptos conceden al afectado hubieran de ceder ante razones de interés público o ante intereses de terceros más dignos de protección. Si el órgano administrativo responsable del fichero automatizado invocase lo dispuesto en este apartado, dictará resolución motivada e instruirá al afectado del derecho que le asiste a poner la negativa en conocimiento del director de la Agencia de Protección de Datos o, en su caso, del órgano equivalente de las Comunidades Autónomas".

La negativa a la rectificación, cancelación o bloqueo de los datos que resulten inexactos por parte de un funcionario por "razones de interés público" o por "intereses de terceros" tiene en el artículo 22.1 el aspecto positivo de que ello requiere una "resolución motivada". Se trata de una garantía importante, que no existe, como vimos, en el anteriormente citado artículo 21 de la LORTAD. En el artículo 22.2 sí se da la necesidad de resolución motivada, lo que permite un control jurisdiccional que es de resaltar. Sin embargo, a pesar de ello, los motivos por los cuales es posible rechazar el derecho del particular a la rectificación, cancelación o bloqueo de datos son inadmisibles constitucionalmente y no están previstos, como excepción a las garantías del Convenio de 1981, en el artículo 9 de éste. Especialmente nos referimos a las urazones de interés público", que es una circunstancia extremadamente genérica y vaga que permite a la Administración denegar los derechos establecidos en el artículo 14 de la LORTAD, y en el artículo 15, por cualquier motivo, lo que hará en la práctica incontrolable por los tribunales esas decisiones administrativas.

Una vez más, no solamente se vulnera el artículo 18.4 de la Constitución, sino que lo mismo sucede con el 9.3, en el cual el Estado de Derecho se proyecta en el principio de seguridad jurídica. El que pueda denegarse por razones de interés público la rectificación, la cancelación o el bloqueo de los datos personales que resulten inexactos, es una invasión 
ilícita del contenido esencial del artículo 18.4 de la Constitución. En consecuencia, el artículo $\mathbf{2 2 . 2}$ de la LORTAD, en la frase que dice "razones de interés público", es inconstitucional. También consideramos inconstitucional ese artículo en cuanto a la frase «intereses de terceros más dignos de protección", ya que se trata de unos términos mucho más amplios que los empleados por el artículo 9 del Convenio Europeo de 1981 cuando considera como de posible excepción de las garantías establecidas en ese Convenio el que se tomen medidas necesarias en una sociedad democrática para la uprotección de la persona concernida y de los derechos y libertades de otras personas". Parece claro que los términos "derechos y libertades" son mucho más concretos y específicos que los términos "intereses" que emplea el artículo 22.2.

En suma, el artículo 22.2 vulnera el Convenio de 1981 y, en consecuencia, el artículo 18.4 de la Constitución, en relación con el 9.3. Debe considerarse inconstitucional en su integridad.

\section{Disposición Final Segunda}

La Disposición Final Segunda de la LORTAD dice:

"El Gobierno, previo informe del Director de la Agencia de Protección de Datos, podrá extender la aplicación de la presente Ley, con las modificaciones y adaptaciones que fuesen necesarias, a los ficheros que contengan datos almacenados en forma convencional y que no hayan sido sometidos todavía o no estén destinados a ser sometidos a tratamiento automatizado".

Estamos ante una remisión en blanco al Gobierno para que amplíe la Ley, cuando lo considere oportuno, a los ficheros que contengan datos almacenados en forma convencional. Se trata, sin duda, de una regulación que directamente afecta a derechos fundamentales, en este caso referida a ficheros convencionales. Es inaceptable, de acuerdo con el artículo 53.1 de la Constitución, que el poder ejecutivo regule estás materias. No estamos ante un caso de delegación legislativa, pero, aunque así fuese, ésta (art. 82 de la Constitución) no puede extenderse a lós derechos fundamentales. Ello contradice el principio de jerarquía normátiva (art. $9.3 \mathrm{CE}$ ). 
A la vista de lo anterior, la Disposición Final Segunda resulta ser inconstitucional, en cuanto contraria al artículo 53.1 de la Constitución, ya que se trata de un desarrollo del artículo 18 de la Constitución, ya que se refiere a ficheros no automatizados, que afectan al derecho a la intimidad, y ése es su sentido. En la medida en que se trata de desarrollar el artículo 18 de la Constitución no es posible aceptar que eso sea una competencia trasladable al Gobierno. Es competencia privativa del Parlamento, y la regulación correspondiente, como señala el artículo 53.1 de la Constitución, es la Ley.

\section{CONCLUSIONES}

De las anteriores consideraciones deducimos que en la LORTAD existen diversos preceptos contrarios a la Constitución. Son los siguientes:

- Artículo 5.3, por ser contrario al Convenio del Consejo de Europa de 1981, y, en consecuencia, contrario al artículo 18.4 de la Constitución española.

- Artículo 17.1, por ser contrario al artículo 53.1 de la Constitución, en relación con el artículo 24.1.

- Artículo 19.1, en cuanto contrario al artículo 18.4 de la Constitución, en relación con los artículos 9.3 y 53.1 de la misma.

- Artículo 20.2 y 3 , en cuanto contrario al artículo 18.4 de la Constitución.

- Artículo 21.1, por ser contrario al artículo 18.4 de la Constitución.

- Artículo 22.1, en la frase «impida o dificulte gravemente el cumplimiento de las funciones de control y verificación de las Administraciones Públicas", en cuanto contrario al artículo 18.4 de la Constitución Española y al Convenio Europeo de 1981.

- Artículo 22.2, igualmente contrario al artículo 18.4 de la Constitución en relación con el Convenio de 1981. 
- Disposición Final Segunda, en cuanto contraria al artículo 53:1 de la Constitución y al artículo 9.3 de la Constitución (principio de jerarquía normativa).

Éste es mi Dictamen, que someto gustoso a cualquier otro mejor fundado en Derecho.

Madrid, a 8 de enero de 1991.

Fdo.: Diego López Garrido

Catedrático de Derecho Constitucional. 